\title{
Vertical migration during the life history of the intertidal gastropod Monodonta labio on a boulder shore
}

\author{
Yoshitake Takada* \\ Amakusa Marine Biological Laboratory, Kyushu University, Amakusa, Kumamoto 863-25, Japan
}

\begin{abstract}
Environmental and biological conditions of the intertidal zone vary according to tidal level. Monodonta labio (Gastropoda; trochidae) occurs over the whole range of the intertidal zone, but juveniles occur only in the mid intertidal zone. In this study, vertical migration of this snail was investigated by mark-recapture techniques for 1 yr at Amakusa, Japan. Snails migrated vertically throughout the year, but varied with season and size. Generally, juvenile snails ( $<7 \mathrm{~mm}$ in shell width) did not actively migrate. Upward migration was conspicuous only in small snails ( 7 to $10 \mathrm{~mm}$ ) in summer. Downward migration was greatest in the larger size classes. Thus, large snails $(\geq 13 \mathrm{~mm})$ gradually migrated downward to the lower zone. Seasonal fluctuations in the vertical distribution pattern of $M$. labio could be explained by this vertical migration. Possible factors affecting this vertical migration and the adaptive significance of migration in the life history of $M$. labio are discussed.
\end{abstract}

KEY WORDS: Seasonal migration - Size $\cdot$ Herbivorous snail · Life history Intertidal zone

\section{INTRODUCTION}

Vertical migration of intertidal gastropods is one of the main factors determining vertical distribution (Smith \& Newell 1955, Frank 1965, Breen 1972, Gallagher \& Reid 1979, review in Underwood 1979), and is sometimes manifested as intraspecific size differences at different tidal levels (Paine 1969, McQuaid 1981. 1982, McCormack 1982). Vermeij (1972) reviewed the evidence for intraspecific shore-level size gradients and postulated that size gradient distributions reflected adaptations to minimize mortality of pre-reproductive age classes. According to his explanation, migration after maturity to sites more susceptible to mortality is compensated for by other factors, such as increased reproductive output.

Species that migrate experience various types of microhabitats during their life history. Several factors are considered to affect the migratory habits of snails (reviewed by Underwood 1979), such as avoidance of competition (Branch 1975), escape from predators

•E-mail: yotaksca@mbox.nc.kyushu-u.ac.jp
(McQuaid 1982), escape from strong wave action (McQuaid 1981), and maximization of reproductive output (Paine 1969). As growth rate, survival rate, and fecundity vary with tidal level, the life history of individual snails can be considered to be determined by their migration history. Life history theory (Stearns 1992, Clark 1993) predicts that snails will select the optimal migration pattern so as to maximize their fitness. In order to assess this hypothesis, it is necessary to estimate the timing and the magnitude of their migration to other habitats.

Monodonta labio (Linné, 1758) is a herbivorous snail which grazes on microalgae. In Asamushi, north Japan, Kojima (1962) reported that $M$. labio occurred in the lower half of the rocky shore during most of the year, and migrated upwards during the spawning season in summer. In Amakusa, south Japan, M. labio lives over the whole intertidal zone, while recruitment occurs only in the mid intertidal zone (Takada 1992, unpubl.). On European shores, vertical migration of $M$. lineata has been estimated from seasonal changes in vertical distribution (Williams 1965, Desai 1966, Underwood 1973); this species appeared to move upward in summer. However, changes in vertical dis- 
tribution patterns of snails may not be the result of vertical migration because recruitment or mortality may occur in restricted tidal zones, or the vertical distribution may be segregated by size, giving a false impression of migration patterns.

In this paper, migration of Monodonta labio between 3 intertidal zones was investigated using a combination of quantitative quadrat sampling and mark-recapture techniques. Magnitudes of vertical migration were expressed by Vertical Migration Indices (VMIs), which represent frequencies of individuals migrating to different tidal zones. The factors affecting timing and direction of vertical migration and implication for the life history of $M$. labio are discussed.

\section{MATERIALS AND METHODS}

Study area and species. Field studies were carried out on a moderately exposed boulder shore on the eastern side of Magarizaki spit (32 $31^{\prime} \mathrm{N}, 130^{\circ} 02^{\prime} \mathrm{E}$ ), on Amakusa Shimo-shima Island, west Kyushu, Japan. The whole intertidal zone of this shore is covered by oval boulders with diameters of less than $50 \mathrm{~cm}$. Generally, wave action on this shore is very weak and only infrequently overturns the boulders. Tides are semidiurnal with a tidal range of $3.3 \mathrm{~m}$ from MLWS to MHWS. Surface water temperature ranged from $12^{\circ} \mathrm{C}$ in winter to $27^{\circ} \mathrm{C}$ in summer. Mori \& Tanaka (1989) and Takada \& Kikuchi (1990) have described the environmental characteristics and community structure of this area in detail.

Monodonta labio grazes on epilithic microalgae. It forages on the upper surface of a boulder, and rests under the boulder while inactive. During a tidal period on the gently shelving shore, normal foraging excursions by $M$. labio were of insufficient duration and length to enable the animal to move from one shore level to another. Thus, during the low tide surveys, any movements of $M$. labio would not have contributed an error to the determination of the migration patterns of the snails. Reproduction in $M$. labio takes place in summer (Sumikawa 1958, Kojima 1962, Takada unpubl.). At Amakusa, the maturation size of $M$. labio is about $8 \mathrm{~mm}$ in shell width (Takada unpubl.), and newly recruited small snails (shell width $<5 \mathrm{~mm}$ ) are found only in the mid intertidal zone in winter (Takada unpubl.).

Mark-recapture experiments. The study area was a narrow rectangular area of $550 \mathrm{~m}^{2}$, measuring $10 \mathrm{~m}$ along and $55 \mathrm{~m}$ perpendicular to the shore. In this area, 4 transect lines were set at $2.5 \mathrm{~m}$ intervals at 11 tide levels to form a sampling grid. TL1 (Tide Level 1) was located $0.5 \mathrm{~m}$ below MHWS and TL11 was located $0.1 \mathrm{~m}$ above MLWS. The 11 tide levels were divided into 3 tidal zones: high (TL1 to 4), mid (TL5 to 7), and low (TL8 to 11 ). Monthly quadrat sampling and markrecapture experiments were conducted at the 44 intersection points of this grid from October 1987 to October 1988. The distance between each tide level was $5 \mathrm{~m}$ (about $25 \mathrm{~cm}$ elevation). Four $50 \times 50 \mathrm{~cm}$ quadrats were set around the intersection points. Thus, 16 quadrats at each tide level were sampled each month. All Monodonta labio in each quadrat were collected and their shell widths (maximal diameter at the aperture) measured with vernier calipers $( \pm 0.05 \mathrm{~mm})$. Shells were marked with non-toxic paints (Paint Marker, Mitsubishi, Japan) and coated with glue (Aron-Alpha, Konishi, Japan) at the outer margin of the aperture. Color combinations were changed with sampling month and sampling points. Thus, snails collected from the same intersection point in the same month were painted with the same color combination. The snails were released at the same points from which they were caught within $36 \mathrm{~h}$ after collection. In order to show size differences in vertical migration patterns, snails were divided into 4 size classes: juveniles (shell width $<7 \mathrm{~mm}$ ), small ( 7 to $10 \mathrm{~mm}$ ), medium (10 to $13 \mathrm{~mm}$ ), and large $(\geq 13 \mathrm{~mm})$. Although the handling disturbance changed the snails' behavior for a few days (author's pers obs.), considering the sampling interval and the mobility of the snails, any bias caused by the previous sampling was believed to be negligible.

Magnitude of vertical migration of Monodonta labio among the 3 tidal zones is expressed as Vertical Migration Index (VMI). In this context VMI is defined as the probability of migration from one of the 3 tidal zones to the other zone(s) during a certain period. Considering the original zone and the direction of migration, there are 4 types of VMI: (1) VMI-HM, migration from the high to the lower zones; (2) VMI-MH, migration from the mid to the high zone; (3) VMI-ML, migration from the mid to the low zone; and (4) VMI-LM, migration from the low zone to the upper zones. VMIs were estimated from the percentage of recaptured snails which migrated from the original tidal zone within a 2 mo period relative to the total number of recaptured snails which were released in that particular zone. A 2 mo period was adopted for this study because it was considered adequate to ensure a sufficient number of recaptured snails for the estimation of VMI and to eliminate any effects of mortality.

Statistical significance of homogeneity in VMIs was examined by $G$-test (Sokal \& Rohlf 1981), and 3-way analysis was carried out. The 3 factors were the 4 snail size classes ( $<7 \mathrm{~mm}, 7$ to $10 \mathrm{~mm}, 10$ to $13 \mathrm{~mm}, \geq 13 \mathrm{~mm}$ ), 6 seasons (Oct-Dec, Dec-Feb, Feb-Apr, Apr-Jun, Jun-Aug, Aug-Oct), and 2 migration modes (migratory and resident). Maximally nonsignificant sets were determined over each size class and season. 
Fig. 1 Monodonta labio. Seasonal changes in vertical distribution. Horizontal bars represent $95 \%$ confidence limit of the density (per $\mathrm{m}^{2}$, number of quadrats $=16$ ) at each tide level

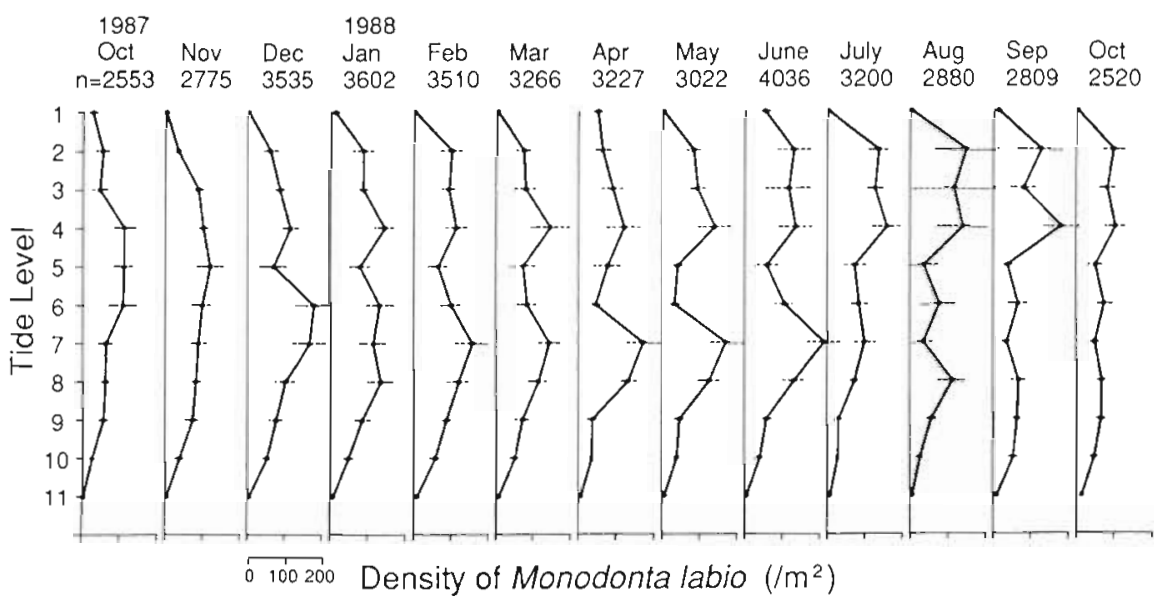

Computer simulation. To represent the cumulative effect of vertical migration on the vertical distribution of Monodonta labio, Monte-Carlo computer simulations were carried out. Hypothetical snails ( $\mathrm{n}=1000$ ) migrated in proportion to the observed VMIs and grew at the rate previously observed by Takada (1995). To imitate natural conditions (Takada 1995, unpubl.), initial size of the hypothetical snails was fixed at $5 \mathrm{~mm}$ and initial position of the snails was the mid zone. The simulations were carried out bimonthly from December and from April so as to show the effects of the recruitment season. During the simulations, mortality was not considered.

\section{RESULTS}

\section{Vertical distribution}

The study area covered the full vertical range of Monodonta labio, and the densities at the extremes of the range (TL1 and TL11) were very low throughout the year (Fig. 1). The vertical distribution fluctuated seasonally, showing a single mode in the mid zone in

Table 1. Monodonta labio. Three-way interaction table for vertical migration indices (VMIs) using $G$-statistics. The 3 factors are (A) size class, $(B)$ season, and (C) migration mode. VMI-HM: migration from the high to the lower zones; VMI-MH: migration from the mid to the high zone; VMI-ML: migration from the mid to the low zone; VMI-LM: migration from the low to the upper zones

\begin{tabular}{|c|c|c|c|c|c|c|c|c|}
\hline \multirow[t]{2}{*}{ Factors } & \multicolumn{2}{|c|}{ VMI-HM } & \multicolumn{2}{|c|}{ VMI-MH } & \multicolumn{2}{|c|}{ VMI-ML } & \multicolumn{2}{|c|}{ VMI-LM } \\
\hline & $\mathrm{df}$ & $G$ & $\mathrm{df}$ & $G$ & $\mathrm{df}$ & $G$ & $\mathrm{df}$ & G \\
\hline$G_{\mathrm{ABC}}$ & 14 & 21.6 & 15 & 23.2 & 15 & 21.5 & 15 & $29.6^{\circ}$ \\
\hline$G_{\mathrm{AC}(\mathrm{B})}$ & 17 & $41.0^{\circ}$ & 18 & $38.9^{*}$ & 18 & $118.0^{\circ} \mathrm{c}$ & 18 & $33.2^{\circ}$ \\
\hline$G_{B C(A)}$ & 19 & $31.7^{\circ}$ & 20 & $46.2 \cdots$ & 20 & $53.4^{\cdots}$ & 20 & $34.8^{\circ}$ \\
\hline
\end{tabular}

winter (Oct-Jan) and a double mode in the high zone and the lower mid zone in summer (Mar-Aug).

\section{Estimation of VMI}

Vertical migration occurred throughout the year (Fig. 2), and the number of recaptured snails varied with snail size, tidal zone, and season. No statistically significant 3-factor interactions (snail size, season, or migration) were detected, except for VMI-LM (Table 1). Both of the 2-factor interactions (snail sizemigration and season-migration) were statistically significant.

VMIs differed between size classes and fluctuated seasonally. Juvenile snails did not migrate as actively as those in the other size classses (Fig. 2a). Most of their VMIs were lower than 15\%, except for VMI-LM in summer (Apr-Aug). For the small snails, seasonal fluctuations in all VMIs were statistically significant (Table 2). However, VMI-HM was low throughout the year (Fig. 2b). Small snails in the mid zone migrated upward in summer (VMI-MH, 42.3\% Jun-Aug), but downward in winter (VMI-ML, 32.1\% Dec-Feb). During April to August, upward migration from the low zone (VMI-LM) was conspicuous in the small snails. For the medium size snails, no statistically significant seasonal fluctuations in VMIs were detected (Table 2). VMI-HM and VMI-MH were low throughout the year, while the migration ratios for VMI-ML were 18 to $49 \%$ (Fig. 2c). VMI-LM in the medium size snails was very low (maximum was $7.1 \%$ Aug-Oct) throughout the year. For the large snails, VMI-HM and VMI-ML were very high at $100 \%$ and $75 \%$ respectively in December to February (Fig. 2d). From the high zone, large snails migrated 
(a) $<7 \mathrm{~mm}$

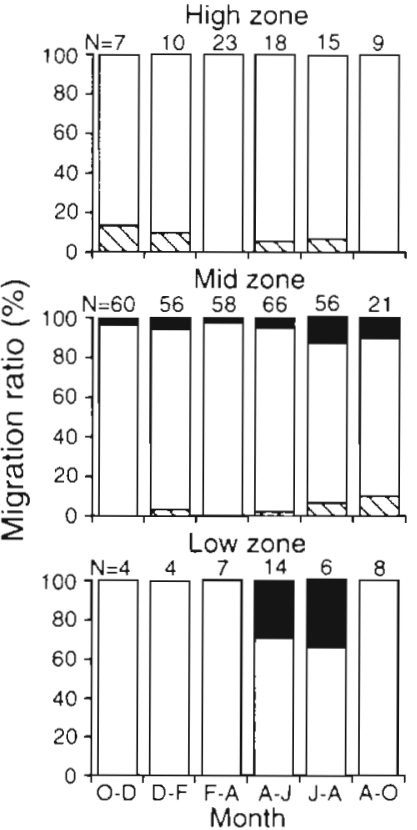

(b) $7-10 \mathrm{~mm}$
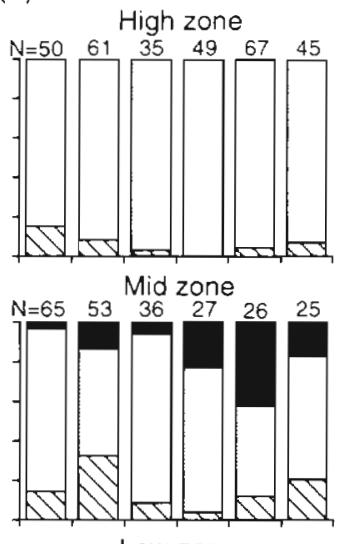

Low zone

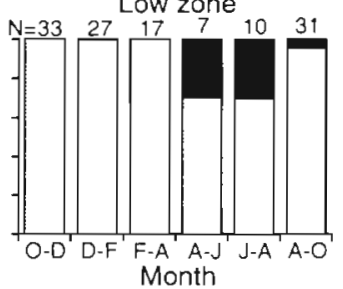

(c) $10-13 \mathrm{~mm}$

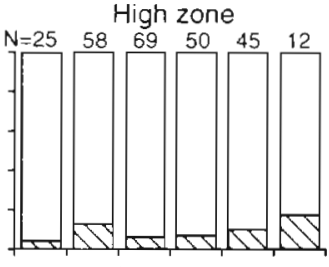

Mid zone
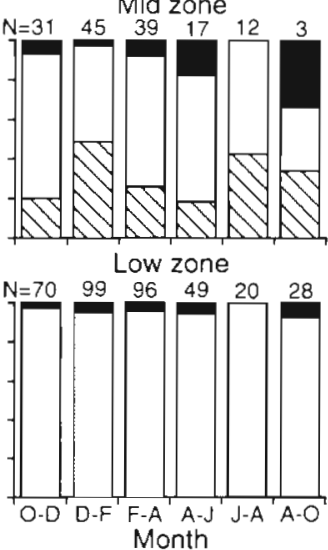

(d) $\geqq 13 \mathrm{~mm}$
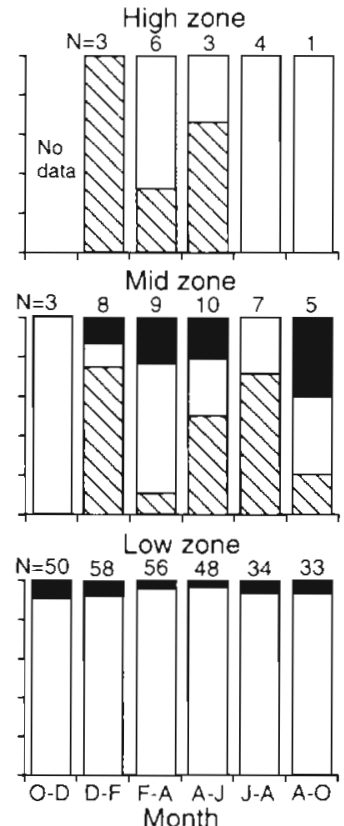

Fig. 2. Monodonta labio. Vertical migration indices (VMIs) in the 3 tidal zones during 2 mo periods. Black bars: upward migration; shaded bars: resident; hatched bars: downward migration. (a) Juvenile snails ( $<7 \mathrm{~mm}$ ), (b) small snails ( 7 to $10 \mathrm{~mm}$ ), (c) medium size snails (10 to $13 \mathrm{~mm}$ ), and (d) large snails ( $\geq 13 \mathrm{~mm}$ ). Number of recaptured snails within each 2 mo period is listed above each column

downward from December to June, while from the mid zone, they migrated downward throughout the year except from October to December. Throughout the year, a few large snails migrated upward from the low zone (VMI-LM).

In summary, the magnitude of downward migration (VMI-HM and VMI-ML) became higher with increase

(a) December cohort
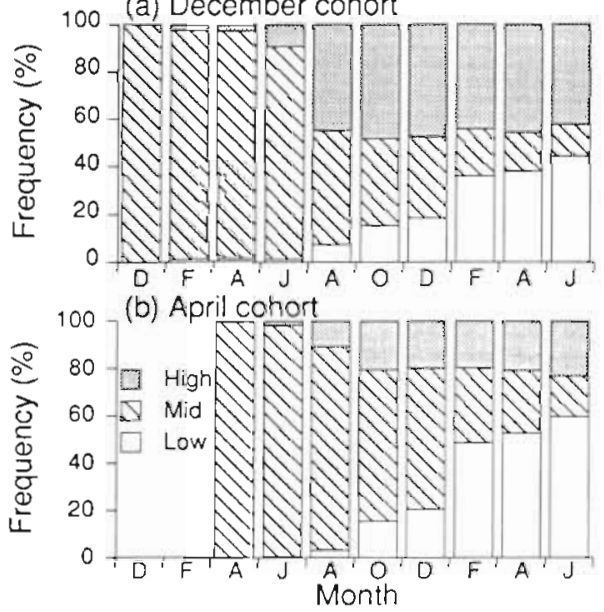

Fig. 3. Monodonta labio. Sumulated vertical distribution of hypothetical snails $(n=1000$ ) estimated using the VMIs shown in Fig. 2 and previously established growth rates (Takada 1995) in size class (Table 3). Upward migration (VMI-MH and VMI-LM) was conspicuous in the juvenile and small snails in summer (Table 3 )

\section{Simulated distribution}

The results of the Monte-Carlo simulations showed that the frequency with which hypothetical individuals stayed in the mid zone decreased with time (Fig. 3). After $8 \mathrm{mo}$, frequencies of occurrence in the high zone of the December cohort were higher than those of the April cohort, while frequencies of occurrence in the low zone showed the opposite trend. At the end of the simulation, mean sizes of the December cohort in the high, mid, and low zones were 12.3, 14.7, and $14.3 \mathrm{~mm}$, respectively, and those of the April cohort were 12.1, 13.9, and $13.6 \mathrm{~mm}$.

\section{DISCUSSION}

\section{Active migration or passive displacement}

On exposed shores, snails are often displaced by wave action (Smith \& Newell 1955, Walsby 1977). However, at Amakusa, wave displacement of Monodonta labio seems unlikely because of weak wave 
Table 2. Monodonta labio. Unplanned test of homogeneity for the seasonal factor using $G$-statistics $\left(G_{B C(A)}\right.$ as in Table $1_{i}$ $\mathrm{df}=5$. Calculations were carried out separately for each VMI (VMIs as in Table 1). FA: Feb-Apr; AJ: Apr-Jun; JA: Jun-Aug; AO: Aug-Oct; OD: Oct-Dec; DF: Dec-Feb. When there is significant heterogenelty among seasons, maximally nonsignificant sets are underlined

\begin{tabular}{|c|c|c|c|c|}
\hline Size $(\mathrm{mm})$ & VMI-HM & VMI-MH & VMI-ML & VMI-LN \\
\hline$<7$ & 4.7 & 7.4 & $122^{\circ}$ & 10.4 \\
\hline $7-10$ & $11.9^{\circ}$ & $25.5^{\cdots} \cdots$ & $15.3^{\cdots}$ & $18.7^{\circ}$ \\
\hline $10-13$ & 3.6 & 7.8 & 11.0 & 3.1 \\
\hline$\geq 13$ & $11.6^{\circ}$ & 5.5 & $14.8^{\circ}$ & 2.6 \\
\hline $\begin{array}{l}\operatorname{Sum}\left(=G_{\mathrm{BC}(\mathrm{A})}\right) \\
\mathrm{df}\end{array}$ & $\begin{array}{l}31.7^{\circ} \\
19\end{array}$ & $\begin{array}{l}46.2 \cdots \\
20\end{array}$ & $\begin{array}{l}53.4^{\cdots} \\
20\end{array}$ & $\begin{array}{c}34.8^{\circ} \\
20\end{array}$ \\
\hline
\end{tabular}

VMI-HM (migration from the high to the lower zones)

$7-10 \mathrm{~mm} \quad$ A.J FA JA AO DF OD

$\geq 13 \mathrm{~mm}$ JA AO FA AJ DF

VMI-MH (migration from the mid to the high zone)

7-10 mm OD FA DF AO AJ JA

VMI-ML (migration from the mid to the low zone)

$<7 \mathrm{~mm} \quad O D$ FA AJ DF JA AO

7-10 mm AJ FA JA OD AO DF

$\geq 13 \mathrm{~mm} \quad$ OD FA AO AJ JA DF

VMI-LM (migration from the low to the upper zones)

$7-10 \mathrm{~mm} \quad$ OD DF FA AO AJ JA

${ }^{d} \mathrm{df}=4$, due to the lack of data during October to

December

$\cdot p<0.05, \cdots p<0.01, \cdots p<0.001$

action and the high availability of safe refuges such as the undersides of boulders. Underwood (1977) reported that Austrocochlea constricta, a closely related genus of Monodonta, can migrate over $110 \mathrm{~cm}$ in $2 \mathrm{~d}$. M. labio have been observed to move about $90 \mathrm{~cm}$ in a day (Takada unpubl.). Thus, the migration of $M$. labio observed in this locality was considered to be the result of active movement of the snails.

\section{Distribution and migration}

Seasonal fluctuation in the vertical distribution of Monodonta labio is controlled by the vertical migration patterns of individuals. By prediction based on knowledge of the population biology of $M$. labio, its recruitment (Takada unpubl.) and vertical migration, the main migration routes on the shore can be estimated. Juveniles recruit to the mid zone in winter. By spring, they become small snails and some migrate upward, thus reducing the density in the mid zone, although some snails migrate from the low to the mid zone during summer These small snails remain in the high zone and become medium size snails by the next winter. Those staying in the mid zone grow faster than the upward migrants (Takada 1995). By the next summer, both of these groups become large and migrate downward to the low zone.

Vermeij (1972) suggested that intraspecific shorelevel size gradients of intertidal gastropods are a response to the gradient of pre-reproductive mortality. He proposed 2 types of gradients: (1) shell size of upper shore species increases in an upshore direction; (2) shell size of lower shore species decreases in an upshore direction. In the type (1) gradient, mortality is

Table 3. Monodonta labio. Unplanned test of homogeneity for the size factor using $G$-statistics $\left(G_{A C \mid B}\right)$ as in Table $1 ; \mathrm{df}=3$ ). Juv: $<7 \mathrm{~mm}$; Sml: 7 to $10 \mathrm{~mm}$; Med: 10 to $13 \mathrm{~mm}$; Lrg: $\geq 13 \mathrm{~mm}$ Calculations were carried out separately for each VMI (VMIs as is Table 1). When there is significant heterogeneity among size classes, maximally nonsignificant sets are underlined

\begin{tabular}{|c|c|c|c|c|}
\hline Season & VMI-HM & VMI-MH & VMI-ML & VMI-LMI \\
\hline Oct-Dec & $2.1^{\mathrm{d}}$ & 0.9 & $16.6^{\cdots}$ & 4.9 \\
\hline Dec-Feb & $13.7^{\cdots}$ & 5.2 & $40.0^{\cdots}$ & 3.6 \\
\hline Feb-Apr & 7.6 & 5.3 & $20.1^{\cdots}$ & 1.8 \\
\hline Apr-Jun & $13.4^{\cdots}$ & 7.6 & $20.2 \cdots$ & $11.1^{\circ}$ \\
\hline Jun-Aug & 1.5 & $17.0 \cdots$ & $19.5 \cdots$ & $10.4^{\circ}$ \\
\hline Aug-Oct & 2.7 & 2.9 & 1.6 & 1.4 \\
\hline $\begin{array}{l}\operatorname{Sum}\left(=G_{\mathrm{AC}(\mathrm{B})}\right) \\
\mathrm{df}\end{array}$ & $\begin{array}{l}41.0^{\circ} \\
17\end{array}$ & $\begin{array}{c}38.9^{\circ} \\
18\end{array}$ & $\begin{array}{c}118.0 \cdots \\
18\end{array}$ & $\begin{array}{c}33.2^{\circ} \\
18\end{array}$ \\
\hline \multicolumn{5}{|c|}{ VMI-HM (migration from the high to the lower zones) } \\
\hline Apr-Jun & Sml Juv & v Med & Lrg & \\
\hline $\begin{array}{l}\text { VMI-MH (migr } \\
\text { Jun-Aug }\end{array}$ & $\begin{array}{l}\text { ration from t } \\
\text { Med Lrg }\end{array}$ & $\begin{array}{l}\text { the mid to } \\
\text { Juv }\end{array}$ & $\begin{array}{l}\text { the high zon } \\
\text { Sml }\end{array}$ & ne) \\
\hline \multicolumn{5}{|c|}{ VMI-ML (migration from the mid to the low zone) } \\
\hline $\mathrm{Dec}-\mathrm{Feb}$ & Juv $\quad \underline{S m l}$ & Med & Lrg & \\
\hline Feb-Apr & Juv Sml & 1) Lrg & Med & \\
\hline Apr-Jun & Juv Sml & l Med & $\operatorname{Lrg}$ & \\
\hline Jun-Aug & Juv Sml & Med & Lrg & \\
\hline \multicolumn{5}{|c|}{ VMI-LM (migration from the low to the upper zones) } \\
\hline Apr-Jun & $\operatorname{Lrg} \quad \mathrm{Me}$ & ed Sml & Juv & \\
\hline Jun-Aug & Med Lrg & Sml & Juv & \\
\hline
\end{tabular}


caused by physical factors such as high temperature or desiccation. In the type (2) gradient, mortality is generally caused by predation or other biotic interactions. The results of some studies, however, do not conform to these generalizations (Walsby 1977, McQuaid 1981, 1982. McCormack 1982). At Amakusa, Monodonta labio was distributed widely in the intertidal zone and size segregation was found to be complicated (Takada 1992). The relationship between tidal level and the size of M. labio did not fit Vermeij's generalization. Mature snails occurred both in the high and the low zones, while newly recruited juveniles occurred in the mid zone. This unique distribution was maintained by 3 factors: (1) limited recruitment of juveniles in the mid zone (Takada unpubl.), (2) differences in growth rates with tidal level (Takada 1995), and (3) vertical migration (this study). The results of the computer simulation suggested that the month of recruitment modified the vertical distribution pattern of $M$. labio. On the Shima Peninsula, Japan, such size segregated distributions did not occur (Nakano \& Nagoshi 1984), probably because of a steeper shore profile. On a steep shore, snails can migrate all over the intertidal zone within a few days. On the other hand, at Amakusa, the shore slope is so gentle that the snails cannot utilize the whole shore at once.

\section{Life history significance of migration}

Underwood (1979) noted the relationship between reproduction and vertical migration of intertidal gastropods. At Asamushi, north Japan, Kojima (1962) found that Monodonta labio showed upward migration in summer, during its spawning season. At Amakusa, some of the small snails, which were considered to be newly matured adults, migrated upwards in summer, while most of the adults stayed in the high zone or migrated downward to the lower zones. Therefore, it is difficult to generalize that the upward migration of $M$. labio in summer bears any relation to reproductive activity. It would appear that vertical migration was a function of animal size and not maturity

Behavioral and physiological adaptations of snails to desiccation are important for their survival (Garrity 1984, Marchetti \& Geller 1987). On rocky shores, if refuges such as holes and crevices were in short supply, high temperature in summer might cause the large snails to migrate down the shore, while juveniles and small snails could escape into the refuges (Emson \& Faller-Fritsch 1976, Raffaelli \& Hughes 1978). On the boulder shore, all the Monodonta labio escape to the undersides of boulders at low tide in summer, when the maximal temperature is $35^{\circ} \mathrm{C}$ (author's pers. obs.). Because the heat coma temperature of $M$. labio is $39.6^{\circ} \mathrm{C}$ (Cleland \& McMahon 1988), the undersides of boulders are thought to be good refuges for them. There seem to be plenty of refuges on the boulder shore, but it is still possible that the short supply of refuges for large snails causes their downward migration in summer.

Seasonal migration of Acmaea digitalis has been explained as an adaptive behavior to minimize mortality and maximize growth rates (Frank 1965, Breen 1972). Seasonal migration of small Monodonta labio from the mid zone may be explained by seasonal fluctuation in microalgal abundance, which affects the snails' growth rates (Takada 1995). Throughout the year, the growth rate of $M$. labio was higher in the low and mid zones than in the high zone (Takada 1995). However, the difference in growth rate between the 3 zones varied with season and was found to be synchronized with the seasonal fluctuation in microalgal abundance. Small snails migrated downward from the mid to the low zone in winter when the microalgal abundance in the low zone was similar to that in the mid zone. They migrated upward from the mid to the high zone in summer when the microalgal abundance in the high zone was similar to that in the mid zone. They may recognize the change in microalgal abundance between 2 zones during their foraging excursions; however, if microalgal abundance is similar in 2 zones, they may not notice their own migration into the next zone. This suggests that small $M$. labio may select and migrate between tidal zones according to microalgal abundance, not so as to maximize growth rate. For larger snails, although the influence of mortality was not estimated in this study, maximization of growth rate can be considered to influence downward migration.

In some intertidal gastropods, habitat selection plays a major role in maintaining their vertical distribution pattern (review in Underwood 1979, Byers \& Mitton 1981, Janson 1983, Byers 1989). In some cases, preferences in habitat selection change during the snail's life history, e.g. in the South African snails Littorina africana knysnaensis and Oxystele variegata, the tide level preferences differ between juveniles and adults (MCQuaid 1981, 1982). L. a. knysnaensis recruits mainly in the upper region of its distribution zone and juveniles live in the upper region. But the adults are usually found in the lower region. This pattern is maintained by size-specific tidal level preference and size-related tenacity against wave dislodgement. In this study, Monodonta labio changed their position on the shore according to their size. The direction of their migration was modified by the month of recruitment. This suggests that variation in recruitment month may influence the variation of migration route and life history.

In conclusion, Monodonta labio migrated vertically throughout the year, but this varied with season and 
size. Small snails migrated upward in summer. Large snails gradually migrated downward to the low zone throughout the year. Seasonal fluctuation in the vertical distribution pattern could be explained by this vertical migration. Major migration routes of individual $M$. labio were determined by the month of recruitment.

Acknowledgements. I thank Prof. T Kikuchi for giving me the opportunity to study this subject and supervising this work. I acknowledge valuable suggestions for the research design from M. Tanaka. Thanks are due to A. Tamaki, S. Nishihama, and $M$. Aoki for valuable discussions during the course of this study. G. A. Williams and K. Nandakumar critically read the early version of the manuscript. This study was partly supported by a Grant-in-Aid for Scientific Research (63480007) from The Ministry of Education, Science, and Culture, Japan and JSPS Fellowship for Junior Scientist (1182).

\section{LITERATURE CITED}

Branch GM (1975) Mechanisms reducing intraspecific competition in Patella spp.: migration, differentiation and territorial behaviour. J Anim Ecol 44:575-600

Breen PA (1972) Seasonal migration and population regulation in the limpet Acmaea (Collisella) digitalis. Veliger 15: $133-141$

Byers BA (1989) Habitat-choice polymorphism associated with cryptic shell-color polymorphism in the limpet Lottra digitalis. Veliger 32:394-402

Byers BA, Mitton JB (1981) Habitat choice in the intertidal snail Tegula funebralis. Mar Biol 65:149-154

Clark CW (1993) Dynamic models of behavior. An extension of life history theory. TREE 8:205-209

Cleland JD, MCMahon RF (1988) Upper thermal limit of nine intertidal gastropod species from a Hong Kong rocky shore in relation to vertical distribution and desiccation associated with evaporative cooling. In: Morton B (ed) Proceedings of the Second International Marine Biological Workshop: the marine flora and fauna of Hong Kong and southern China, Hong Kong, 1986. Hong Kong University Press, Hong Kong, p 1141-1152

Desai BN (1966) The Biology of Monodonta lineata (da Costa). Proc malacol Soc Lond. 37:1-17

Emson RH, Faller-Fritsch RJ (1976) An experimental investigation into the effect of crevice availability on abundance and size-structure in a population of Littorina rudis (Manton): Gastropoda: Prosobranchia. J exp mar Biol Ecol 23:285-297

Frank PW (1965) The biodemography of an intertidal snail population. Ecology 46:831-844

Gallagher SR, Reid GK (1979) Population dynamics and zonation in the periwinkle snail, Littorina angulifera, of the Tampa Bay, Florida, region. Nautilus 94:162-178

Garrity SD (1984) Some adaptations of gastropods to physical stress on a tropical rocky shore. Ecology 65:559-574

Janson K (1983) Selection and migration in two distinct phenotypes of Littorina saxatilis in Sweden. Oecologia 59: $58-61$

Kojima K (1962) On the spawning of a top-shell, Monodonta labio (Linne). Venus Jpn J Malacol 22:200--203

Marchetti KE, Geller JB (1987) The effects of aggregation and microhabitat on desiccation and body temperature of the

This article was submitted to the editor black turban snail, Tegula funebralis (A. Adams, 1855). Veliger 30:127-133

McCormack SMD (1982) The maintenance of shore-level size gradients in an intertidal snail (Littorina sitkana). Oecologia $54: 177-183$

MCQuaid CD (1981) The establishment and maintenance of vertical size gradients in populations of Littorina africana knysnaensis (Philippi) on an exposed rocky shore. J exp mar Biol Ecol 54:77-89

McQuaid CD (1982) The influence of desiccation and predation on vertical size gradients in populations of the gastropod Oxystele variagata (Anton) on an exposed rocky shore. Oecologia 53:123-127

Mori K. Tanaka M (1989) Intertidal community structures and environmental conditions of exposed and sheltered rocky shores in Amakusa, Japan. Publ Amakusa mar biol Lab. Kyushu Univ 10:4 $1-64$

Nakano D, Nagoshi M (1984) Growth and death in an intertidal population of Monodonta labio (Linnaeus), (Prosobranchia, Trochidae). Venus Jpn J Malacol 43:60-71 (in Japanese with English summary)

Paine RT (1969) The Pisaster-Tegula interaction: prey patches, predator food preference, and intertidal community structure. Ecology 50:950-961

Raffaelli DG. Hughes RN (1978) The effects of crevice size and availability on populations of Littorina rudis and Littorina neritoides. J Anim Ecol 47:71-83

Smith JE, Newell GE (1955) The dynamics of the zonation of the common periwinkle [Littorina littorea (L.)] on a stony beach. J Anim Ecol 24:35-56

Sokal RR, Rohlf FJ (1981) Biometry. Freeman, New York, p 691-778

Stearns SC (1992) The evolution of life histories. Oxford University Press, Oxford

Sumikawa S (1958) On the seasonal changes in gonad of Monodonta labio L., with special reference to ovary. Sci Hum Life Fukuoka Women's Univ 4:63-87 (in Japanese with English summary)

Takada Y (1992) Tide level variation of morph frequency and size structure in Monodonta labio (Gastropoda: Trochidae) at several boulder shores in Amakusa. Venus Jpn J Malacol 51:187-195

Takada Y (1995) Variation of growth rate with tidal level in the gastropod Monodonta labio on a boulder shore. Mar Ecol Prog Ser 117:103-110

Takada Y, Kikuchi T (1990) Mobile molluscan communities in boulder shores and the comparison with other intertidal habitats in Amakusa. Publ Amakusa mar biol Lab, Kyushu Univ 10:145-168

Underwood A.J (1973) Studies on zonation of intertidal prosobranch molluscs in the Plymouth region. J Anim Ecol 42 : $353-372$

Underwood AJ (1977) Movement of intertidal gastropods. $J$ exp mar Biol Ecol 26:191-201

Underwood AJ (1979) The ecology of intertidal gastropods. Adv mar Biol 16:111-210

Vermeij GJ (1972) Intraspecific shore-level size gradients in intertidal molluscus. Ecology 53:693-700

Walsby JR (1977) Population variation in the grazing turbinid Lunella smaragda (Mollusca: Gastropoda). NZ J mar Freshwat Res 11:211-238

Williams EE (1965) The growth and distribution of Monodonta lineata (da Costa) on a rocky shore in Wales. Fld Stud 2: $189-198$ 